\title{
Exercise enhances memory consolidation in the aging brain
}

\author{
Shikha Snigdha ${ }^{1}{ }^{*}$, Christina de Rivera ${ }^{2}$, Norton W. Milgram ${ }^{2}$ and Carl W. Cotman ${ }^{1}$ \\ 1 Institute for Memory Impairments and Neurological Disorders, University of California, Irvine, CA, USA \\ ${ }^{2}$ CanCog Technologies Inc., Toronto, ON, Canada
}

\section{Edited by:}

Philip P. Foster, The University of Texas Health Science Center at Houston, USA

\section{Reviewed by:}

Brenda J. Anderson, Stony Brook University, USA

Michael Valenzuela, University of Sydney, Australia

*Correspondence:

Shikha Snigdha, Institute for Memory Impairments and Neurological

Disorders, University of California, 1226 Gillespie NRF, Irvine,

CA 92697-4540, USA

e-mail:ssnigdha@uci.edu
Exercise has been shown to reduce age-related losses in cognitive function including learning and memory, but the mechanisms underlying this effect remain poorly understood. Memory formation occurs in stages that include an initial acquisition phase, an intermediate labile phase, and then a process of consolidation which leads to long-term memory formation. An effective way to examine the mechanism by which exercise improves memory is to introduce the intervention (exercise), post-acquisition, making it possible to selectively examine memory storage and consolidation. Accordingly we evaluated the effects of post-trial exercise (10 min on a treadmill) on memory consolidation in aged canines both right after, an hour after, and $24 \mathrm{~h}$ after acute exercise training in concurrent discrimination, object location memory (OLM), and novel object recognition tasks. Our study shows that post-trial exercise facilitates memory function by improving memory consolidation in aged animals in a time-dependent manner. The improvements were significant at $24 \mathrm{~h}$ post-exercise and not right after or $1 \mathrm{~h}$ after exercise. Aged animals were also tested following chronic exercise (10 min/day for 14 consecutive days) on OLM or till criterion were reached (for reversal learning task). We found improvements from a chronic exercise design in both the object location and reversal learning tasks. Our studies suggest that mechanisms to improve overall consolidation and cognitive function remain accessible even with progressing age and can be re-engaged by both acute and chronic exercise.

Keywords: exercise, memory consolidation, aging, concurrent discrimination, object location, novel object recognition, reversal learning, dogs

\section{INTRODUCTION}

Observational studies have identified physical activity (exercise) as one of the three main modifiable risk factors for developing $\mathrm{AD}$ and dementia (Barnes and Yaffe, 2011). Exercise is known to promote brain health and delay the onset of cognitive decline in aging and AD. Exercise has been reported to increase synaptic plasticity and long-term potentiation (LTP; van Praag et al., 1999; Liu et al., 2011; Dao etal., 2013), upregulate brain derived neurotrophic factor (BDNF) expression, and reduce accumulation of reactive oxygen species (Radak et al., 2001; Berchtold et al., 2002). Thus, exercise primes the brain to access mechanisms that can improve cognitive faculties and reduces the detrimental effects of molecular and synaptic changes that occurs with age (van Praag et al., 2005; Kronenberg et al., 2006; Cotman and Berchtold, 2007; Cotman et al., 2007; Kannangara et al., 2011).

Using a canine model of aging, we have shown that behavioral enrichment consisting of exercise, enriched housing and cognitive enrichment can significantly improve the cognitive capacity of old beagles. In these past studies we demonstrated an association between long-term enrichment and exercise and improved cognitive function (Milgram etal., 2004; Snigdha etal., 2011; Fahnestock etal., 2012). Our results were indicative of a causal link between exercise and improved learning and memory.

The present experiments sought to explore this relationship further to better understand how exercise enhances memory. One broadly accepted model of memory formation assumes that memory occurs in phases which include, an acquisition phase (learning), followed by an intermediate labile phase, and then a process of consolidation which leads to long-term memory formation (McGaugh, 1966, 2000; Bekinschtein et al., 2007; McKenzie and Eichenbaum, 2011). Memory consolidation occurs by a cascade of molecular and cellular events which results in stable synaptic and network modifications (Davis and Squire, 1984; McGaugh, 2000; Bekinschtein et al., 2007; Park and Poo, 2013). In these experiments our main focus was on evaluating the role of exercise in promoting memory consolidation. While the effect of exercise on cognitive function has been extensively studied, the specific role of exercise in promoting consolidation is yet to be explored.

One effective way to examine memory consolidation is the use of post-trial interventions (Cahill and Alkire, 2003; Segal et al., 2012). By introducing exercise after the learning phase, it is possible to test effects of exercise on memory storage and consolidation selectively in such intervention studies. Therefore, we designed a study to examine the effects of an acute post-learning exercise intervention in aged animals. It has been suggested that consolidation requires a significant involvement of the hippocampus in the first stages and later requires a greater involvement of the taskrelevant cortical areas (McKenzie and Eichenbaum, 2011). Thus, due to the task specificity and time-contingency, it is critical to use different behavioral tasks to assess the effects of an intervention on consolidation. Consequently, in this study we evaluated the effects of exercise on memory consolidation both right after and 
$24 \mathrm{~h}$ after the exercise training in a several different behavioral paradigms.

Specifically, we evaluated the effects of acute exercise in a concurrent discrimination task which is known to be medial temporal lobe (MTL)-dependent in humans (Squire et al., 1988; Hood et al., 1999). MTL involvement in memory processes has been studies for more than half a century now, particularly after the case of patient HM was reported (Scoville and Milner, 1957). The networks of MTL structures include the hippocampus and surrounding cortices such as perirhinal, entorhinal, and parahippocampal cortices (Squire et al., 2004). Many of these regions, including the hippocampus (Bach etal., 1999; Lister and Barnes, 2009) and perirhinal cortex (Burke et al., 2011,2012) are known to be susceptible to aging. In this study we utilized tasks which would map to these specific regions of the MTL. Specifically, the object location memory (OLM) and novel object recognition (NOR) tasks which rely on the hippocampus (Holdstock et al., 2002; Mumby et al., 2002a) and perirhinal cortex respectively (Mumby et al., 2002b; Winters and Bussey, 2005) were used to test and confirm the effects of exercise on memory consolidation. While the OLM task has been shown to be sensitive to age in mice and humans, there have been no studies documenting age-related effects in NOR. Furthermore, neither OLM nor the NOR task has been demonstrated in dogs previously and were specifically developed for this study. A major advantage of using the OLM and NOR tasks is that they allow for testing the effects of single bouts of exercise and do not require pre-training. This provides an excellent tool to study consolidation processes. We also conducted a 2 week exercise study to compare the effects of acute vs. longer term exercise on OLM.

It is now widely accepted that the network of MTL structure are implicated in many but not all kinds, of cognitive and memory functions (Squire, 2004). Thus, in order to test whether the effect of exercise impacted regions other than the hippocampus, aged animals were tested on a reversal learning task. The reversal learning task is a frontal lobe-dependent task (McAlonan and Brown, 2003; Stalnaker et al., 2007) and has been previously described in dogs in several communications (Milgram et al., 1994; Tapp et al., 2003; Head et al., 2008). Performance on this task predominantly relies on executive functions (Lai et al., 1995) and assess loss of inhibitory control in aging (Tapp et al., 2003; Snigdha et al., 2013). It has also been suggested that inhibitory failure disrupts several aspects of overall cognitive function (e.g., working memory) and interferes with encoding and retrieval processes (Hasher and Zachs, 1988; Buckner, 2003). Hence, we evaluated the effect of exercise on the reversal learning task to assess if an intervention that impacts memory consolidation also improves performance of aged animals in a task which relies on inhibitory control.

\section{MATERIALS AND METHODS SUBJECTS}

Twenty-two beagles ranging in age at the start of the study from 10.1 to 11.1 years $($ mean $=10.6$ years, $S D=0.23$, eight males $/ 14$ females) were obtained from the colony at CanCog Technologies Inc. (Toronto, Canada) and housed at the Cancog site during the study. The study protocol was approved by the CanCog
Technologies Institutional Animal Care Committee, and it followed the guidelines of the Ontario Ministry of Agriculture. All animals used for the study were visually examined daily by trained veterinary animal personnel and research staff. All dogs had similar cognitive testing experience, which included pre-training as described previously (Milgram et al., 1994). Veterinary examinations were conducted on all dogs prior to the start of the study to assess their general health and to ensure that visual, auditory, and motor functioning were not compromised. All animals were group-housed indoors, had free access to water, and were fed once daily. The dogs' dietary history included three different diets: standard adult maintenance diet (Purina Pro Plan ${ }^{\circledR}$ Chicken and Rice), the standard diet supplemented with mitochondrial co-factor and antioxidant supplements, or the standard diet supplemented with lipoic acid. In the current study, the two treatment groups (exercise, control) both contained animals from all three dietary conditions and animals from all three dietary groups were distributed equally between control and exercise groups for this study. Housing temperature was held at $21 \pm 6^{\circ} \mathrm{C}$ and relative humidity levels ranged between 15 and 75\%.

\section{GROUP ASSIGNMENTS}

All animal in the study were trained to run on the treadmill, following which, animals were divided into two groups: exercise $(n=11)$ and control (non-exercised; $n=11$ ). For the exercise group, dogs underwent one daily session of treadmill exercise $(10 \mathrm{~min})$ as described below, while control dogs were placed in a metabolic or veri-kennel for $10 \mathrm{~min}$. Both the treatment groups contained a balanced group of animals from all three dietary conditions.

\section{EXERCISE INTERVENTIONS TESTED}

This study investigated the efficacy of different exercise intervention strategies in improving cognitive performance in aged dogs. First, we assessed the effects of post-training exercise session (10 $\mathrm{min}$ ) on subsequent consolidation of the cognitive task. Subjects were tested at 2 timepoints: immediately after the exercise session (concurrent discrimination task), or $1 \mathrm{~h}$ after the exercise session (OLM and NOR tasks), and $24 \mathrm{~h}$ after the exercise session. In addition to testing how post-learning acute exercise affects cognitive performance, we investigated the effects of chronic daily exercise on cognitive function using two different behavioral approaches. It should be noted that colony animals get about $30 \mathrm{~min}$ of exercise daily (i.e., they are let out of the pens or metabolics to run freely in the aisles) and prior to starting on the exercise study all dogs were given this $30 \mathrm{~min}$ of daily exercise. Furthermore, all dogs in this study have previous cognitive testing experience and have been able to perform normally on many cognitive tasks. We have also found that cognitive testing itself is a very positive experience for the dogs and it was evident from daily observations of the entire colony that the dogs were neither depressed nor deprived at the start of this study.

\section{EXERCISE PROTOCOL \\ Habituation}

Exercise group animals were first acclimated to the treadmill for 5 days prior to study initiation to allow animals to build endurance 
and to decrease acute exercise related stress. The habituation began with 4 min of exercise (including $1 \mathrm{~min}$ of warm up and $1 \mathrm{~min}$ to cool down) and was increased $2 \mathrm{~min} /$ day to eventually total $10 \mathrm{~min}$. Animals were equipped with a harness prior to exercise and were allowed to climb on the treadmill voluntarily, or were lifted onto treadmill if assistance was needed. A leash was attached to the harness so that the animal's hind legs did not leave the end of the treadmill belt while walking/trotting.

\section{Daily exercise session}

Animals were allowed to first warm up for $1 \mathrm{~min}$ at the ideal walking pace for that animal, and then exercised at a fast walk or trotting pace for $8 \mathrm{~min}$. The speed was dependent on the animal's abilities. A 1 min cool down was provided at a speed equal to or lower than the warm up speed, depending on the animal's abilities. The total exercise time was $10 \mathrm{~min}$.

\section{Cognitive tasks}

Cognitive function was tested using four cognitive tasks: concurrent testing, reversal learning, OLM, and NOR, in combination with acute or chronic exercise. Effects of acute post-learning exercise on consolidation were tested using the concurrent discrimination task, OLM and NOR, and chronic exercise effects were tested using ORM and Reversal learning task.

\section{The order of testing was as follows}

concurrent discrimination (acute exercise, $n=11$ /group), reversal learning (chronic exercise, $n=11$ /group), OLM (acute exercise, $n=6$ for control group and 5 for exercise group), NOR (acute exercise, $n=8$ /group at $1 \mathrm{~h}, n=7$ for control and 8 for exercise groups at $24 \mathrm{~h}$ ), OLM (chronic exercise, $n=6$ for control and 8 for exercise groups at $1 \mathrm{~h}, n=6 /$ group at $24 \mathrm{~h}$ ). The testing phases were spaced temporally such that at least 4-6 weeks separated each exercise/cognitive phase from the preceding test phase. The testing took place over a 2 year period, and because dogs were old, there was some group attrition due to vision loss, arthritis, cancer, death, or other factors that rendered the animal incapable of participating (e.g., animals that did not engage in the task were also excluded from the analysis). Sample sizes for each testing parameter are indicated in the figure legends.

\section{TESTING ARENAS}

Cognitive testing for the concurrent discrimination and reversal learning tasks was conducted in a canine adaptation of the Wisconsin general testing apparatus, as described previously (Milgram et al., 1994). Briefly, the apparatus consisted of a large holding area where the dog was housed during testing, which was separated from the experimenter by a wooden screen containing a one-way mirror and a hinged door at the bottom. A Plexiglas stimulus tray containing three food wells was pushed through the hinged door by the experimenter so that the dog could access the stimuli and food rewards by sticking its head through adjustable stainless steel gates at the front of the holding area. The tray was removed out of sight during delay and inter-trial intervals. Food reward for correct responses during cognitive testing consisted of approximately $1 \mathrm{~g}$ of wet dog food (Hill's P/D). To mask the presence of the food reward in the negative food wells, the undersides of all stimuli were baited with the same food such that, while able to smell it, the animals could not see or eat it. For all tasks, a partial correction procedure was used in which the dogs were permitted to correct their response after making an error once each session. OLM and NOR testing took place in an open field room (approximately $8 \times 9 \mathrm{ft}$ ) equipped with two cameras to record movement for data analysis.

\section{CONCURRENT DISCRIMINATION TASK}

The concurrent discrimination task measures the ability to remember object-object associations in the presence of active interference. Animals were assessed for object preference prior to discrimination testing, as described below.

\section{Preference testing}

Prior to cognitive testing, animals were presented with a pair of objects, and tested for their preferred object of the pair. Animals were given 20 presentations of four different object pairs, in which each of the object pairs were presented on five occasions. Responses to each object were recorded and all responses were rewarded with a food reward. For each object pair, the object selected most frequently was designated the preferred object and the object selected less frequently was designated the non-preferred object.

\section{Concurrent discrimination testing}

One session consisted of 24 trials, in which the animal was presented with an object pair and was rewarded for choosing their non-preferred object. The 24 trials were separated by a $15 \mathrm{~s}$ intertrial interval, and consisted of four different object pairs presented sequentially six times. Each object pair differed in three dimensions: color (gray or white), size (small, medium, large), and shape. On a first trial, of each object pair, a correction procedure was used, with subjects being allowed to correct their response if they chose incorrectly. Subjects received a maximum of $30 \mathrm{~s}$ to respond to each trial. If a response was not made in the first $15 \mathrm{~s}$ of a trial, verbal coaxing was initiated. A non-response was recorded if the animal did not respond within $30 \mathrm{~s}$.

\section{Testing procedure with exercise}

Animals were tested over the course of 3 days. Day 1: preference testing, Day 2: baseline performance, followed by $10 \mathrm{~min}$ exercise or rest (control group), and retesting in the concurrent discrimination task immediately after the $10 \mathrm{~min}$ exercise/rest interval. Day 3: re-testing $24 \mathrm{~h}$ after the preceding day's exercise session (Figure 1).

\section{OBJECT LOCATION MEMORY}

This task relies on spontaneous exploratory activity and the inherent preference for investigating novelty. Memory is evaluated by the differences in the exploration time of identical objects that are in novel or familiar locations. The effect of exercise on memory consolidation was tested at 1 and $24 \mathrm{~h}$ after an exercise exposure.

Animals were first habituated over 5 days $(10 \mathrm{~min} /$ day $)$ to the empty open field testing room. Following habituation, animals were given a 5 min acquisition session to explore the testing room after two identical objects had been placed in diagonally opposite corners, and the time spent exploring each object was 
recorded. Immediately following the acquisition session, animals in the exercise group were given 10 min treadmill exercise, while control animals remained sedentary. One hour later, memory was assessed. Each animal was led back to the open field room where the location of one of the objects had been changed, and animals were allowed to explore the objects and test room for $5 \mathrm{~min}$. The time spent exploring each object was recorded (Figure 2A).

In a separate experiment, memory was assessed $24 \mathrm{~h}$ after the exercise/rest session: animals underwent an acquisition session ( $5 \mathrm{~min}$ ), followed by exercise/rest (10 $\mathrm{min}$ ), and $24 \mathrm{~h}$ later a memory test in which the location of one of the objects had been changed (Figure 2B). In all experiments, the room and objects were cleaned before and after the acquisition and memory testing for each animal.

\section{NOVEL OBJECT RECOGNITION MEMORY}

Like the OLM task, this task relies on spontaneous exploratory activity and the inherent preference for investigating novelty. Memory is evaluated by the differences in the exploration time of novel and familiar objects. Animals were first individually familiarized (10 min) with the empty open field test room. Following habituation, animals were given a 5 min acquisition session to explore the testing room after two identical objects had been placed in diagonally opposite corners, and the time spent exploring each object was recorded. Immediately following the acquisition session, animals in the exercise group were given 10 min treadmill exercise, while control animals remained sedentary. Memory was assessed 1 and $24 \mathrm{~h}$ after the exercise/rest session (Figure 3). For memory assessment, each animal was led back to the open field room, where one of the objects had been replaced with a novel object, and animals were allowed to explore the objects and test room for $5 \mathrm{~min}$. The time spend exploring each object was recorded. The room and objects were cleaned before and after the acquisition and memory testing for each animal.

\section{CHRONIC EXERCISE PRIOR TO LEARNING: OLM}

To test if long-term exercise improves hippocampal function in aged dogs, animals in the exercise group underwent daily treadmill exercise for 14 consecutive days. Two days later, all animals were given a $5 \mathrm{~min}$ acquisition session to explore two identical objects that had been placed in diagonally opposite corners of the testing room, and the time spent exploring each object was recorded. Retention memory was assessed at 1 and $24 \mathrm{~h}$ after the acquisition trial (Figure 4). For memory assessment, one of the objects had been replaced with an object in a novel location as described above, and animals were allowed to explore the objects and test room for 5 min.

\section{CHRONIC EXERCISE CONCURRENT WITH LEARNING: REVERSAL TASK}

Reversal learning is frontal lobe-dependent task that requires the animal to disregard a previously learned object-object association, and to learn a new association. In this study, after identifying each animal's preferred/non-preferred objects for a given object pair (as described above for the concurrent discrimination task), animals learned to associate a positive food reward with the preferred object. Each daily session consisted of 20 trials (15 s inter-trial interval) where subjects were presented with objects which differed in color and shape, but not in size. Errors were recorded, and once criterion was reached of $\geq 80 \%$ correct responses in a day's session, reversal learning was initiated. During reversal learning, the non-preferred objects became the positive stimulus. Daily errors were recorded, and animals were tested on the reversal phase until the animal achieved reached criterion $(\geq 80 \%$ correct in a single session). For animals in the exercise group, each dog underwent daily exercise (10 min treadmill) immediately prior to the test session, beginning the day of preference testing and continuing through reversal learning (Figure 5). Subjects in the control group remained sedentary in a metabolic or veri-kennel for $10 \mathrm{~min}$. A correction procedure was allowed, such that on the first incorrect response of the first session of learning and reversal, subjects were allowed to correct their response. Days of exercise was determined by the number of days needed to reach criterion.

\section{STATISTICS AND ANALYSIS}

All statistical analyses were conducted using GraphPad Prism. Repeated measures analysis of variance (ANOVA) or one-way ANOVA was used to assess the effects of exercise. Bonferroni post hoc test was conducted where necessary to examine group differences when a significant overall effect was found. Behavior marking was also scored manually while watching the animal in the room for confirmation. For concurrent discrimination and reversal learning tasks, the total number of correct responses and errors made to reach the criteria were used as the main measure respectively. For OLM and NOR tasks, the total time spent exploring objects were used as main measures. Index of discrimination (D1) was calculated by subtracting time spent exploring familiar object/location from time spent exploring novel object/location and discrimination index (DI) was calculated as the ratio of the difference between time spent exploring familiar object/location from time spent exploring novel object/location, and the sum of time spent exploring familiar object/location from time spent exploring novel object/location[(novel - familiar $) /($ novel + familiar $)$.

\section{RESULTS}

\section{ACUTE POST-LEARNING EXERCISE: EFFECTS ON CONSOLIDATION}

Three different tasks were used to assess the effectiveness of postlearning exercise in enhancing memory consolidation: concurrent discrimination learning, OLM and NOR.

\section{CONCURRENT DISCRIMINATION TASK}

The concurrent discrimination task tested the ability of the aged dogs to learn a list of object-pair discriminations ( 24 trials: four object pairs presented six times). To evaluate if post-learning exercise improved performance, animals were tested on the concurrent task (baseline performance), underwent exercise (10 min), or rest (controls), and were retested both immediately after the exercise session and $24 \mathrm{~h}$ later.

Concurrent discrimination testing revealed that an acute session of post-learning exercise enhanced memory performance 

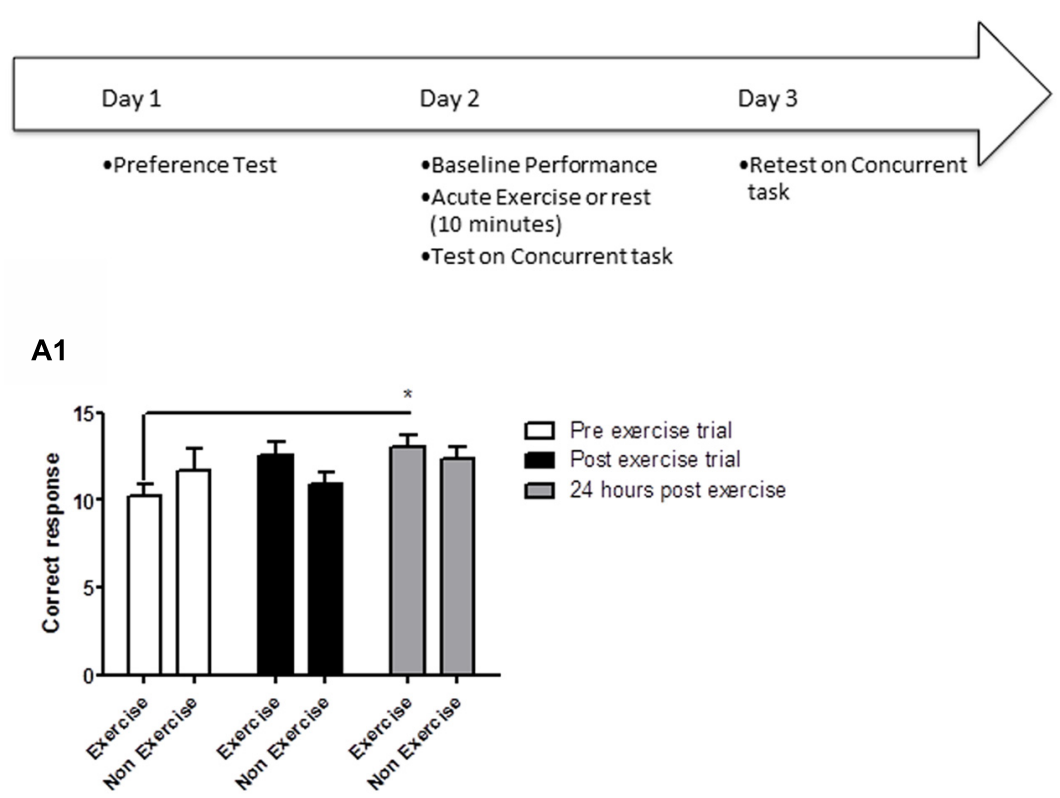

FIGURE 1 | Schematic showing testing on the concurrent discrimination task after acute exercise. Animals were tested on the concurrent task over the course of 3 days. Day 1: preference testing, Day 2: baseline performance, followed by $10 \mathrm{~min}$ exercise or rest (control group), and retesting in the concurrent discrimination task immediately after the 10 min exercise/rest interval. Day 3: re-testing $24 \mathrm{~h}$ after the preceding day's exercise session. (A1) Effect of 10 min of post-trial exercise on performance of aged beagles in the concurrent discrimination task. The figure shows the number of correct response in the concurrent discrimination task conducted first prior to exercise, then immediately after exercise, and finally at $24 \mathrm{~h}$ after the exercise training. At $24 \mathrm{~h}$ post-exercise the animals in the exercise group were significantly improved compared to the pre exercise trial. ${ }^{*} p<0.05$. Significant difference from pre exercise trial. $n=11$ /group, Error bars show \pm SEM. relative to control animals. A mixed factor ANOVA with treatment as the between subjects effect and time of testing as the within subjects factor revealed a significant effect of time $\left[F_{(2,40)}=3.05 ; p<0.05\right]$, but not treatment $\left[F_{(1,20)}=0.16\right.$; $p=\mathrm{NS}]$. The interaction between the two factors was not quite statistically significant $\left[F_{(2,40)}=2.5, p=0.09\right]$. Post hoc analysis demonstrating that exercise animals showed significantly better performance $24 \mathrm{~h}(p<0.05)$ post-exercise, and a trend $(p=0.05)$ for better performance immediately after exercise (Figure 1A1). These data reveal that a single session of post-learning exercise improves memory performance, with a significant improvement observed $24 \mathrm{~h}$ after exercise. These data suggest that postlearning exercise facilitates consolidation of a MTL-dependent task.

\section{OBJECT LOCATION MEMORY}

We next assessed if post-learning exercise improves performance of aged dogs in the OLM task. Testing consisted of an acquisition trial ( $5 \mathrm{~min})$, immediately followed by exercise $(10 \mathrm{~min})$, or rest (controls), and assessment of performance effects at $1 \mathrm{~h}$, or $24 \mathrm{~h}$ post-exercise intervention.

OLM memory testing revealed that an acute session of postlearning exercise improved memory performance relative to controls, but only after $24 \mathrm{~h}$ of consolidation. A mixed factor ANOVA with treatment as the between subjects effect and object location as the within subjects factor revealed no overall interaction $\left[F_{(1,8)}=0.43, p=\mathrm{NS}\right]$ or main effect of treatment $\left[F_{(1,8)}=0.21\right.$, $p=\mathrm{NS}]$. Although there was a significant effect of object location
$\left[F_{(1,8)}=5.31, p<0.05\right]$, post hoc analysis showed no difference between exploration of object locations for either the control or exercise groups ( $p=$ NS) in the acquisition phase of the task at $1 \mathrm{~h}$ (Figure 2A3). There was no significant interaction effect $\left[F_{(1,18)}=0.04, p=\mathrm{NS}\right]$ or main effect of exercise $\left[F_{(1,18)}=1.16\right.$, $p=\mathrm{NS}]$ (Figure 2A2) or location $\left[F_{(1,18)}=0.95, p=\mathrm{NS}\right]$ (Figure 2A2) at the $1 \mathrm{~h}$ post-exercise timepoint. There was also no significant difference in the index of discrimination between groups in the $1 \mathrm{~h}$ retention test ( $p=$ NS, Figure 2A3) or in the DI ( $p=$ NS, Figure 2A4).

For the retention test conducted $24 \mathrm{~h}$ after acquisition, there was no interaction $\left[F_{(1,12)}=3.15, p=\mathrm{NS}\right.$; mixed factor ANOVA] or main effect of exercise $\left[F_{(1,12)}=0.73 ; p=N S\right.$, Figure 2B1] or location $\left[F_{(1,12)}=0.69 ; p=N S\right.$, Figure $\left.2 \mathbf{B 1}\right]$ in initial object exploration in the acquisition phases of the task, revealing that the two objects were equally attended to, and thus equally salient. A mixed factor ANOVA with treatment as the between subjects effect and object location as the within subjects factor revealed that the interaction effect between exercise and object location for the $24 \mathrm{~h}$ retention trial was not significant $\left[F_{(1,11)}=2.08\right.$; $p=\mathrm{NS}]$. There was no significant effect of exercise $\left[F_{(1,11)}=2.35\right.$; $p=0.33$, Figure 2B2] or object location $\left[F_{(1,11)}=0.54 ; p=\mathrm{NS}\right]$ either. However, $24 \mathrm{~h}$ after acquisition, the index of discrimination (Figure 2B3) and the DI (Figure 2B4) revealed that only exercised animals, but not control animals, discriminated between the novel and familiar object locations $(p<0.05$, Student's $t$ test), suggesting that control animals did not consolidate the information into long-term memory. 
Snigdha et al.

Exercise improves memory consolidation

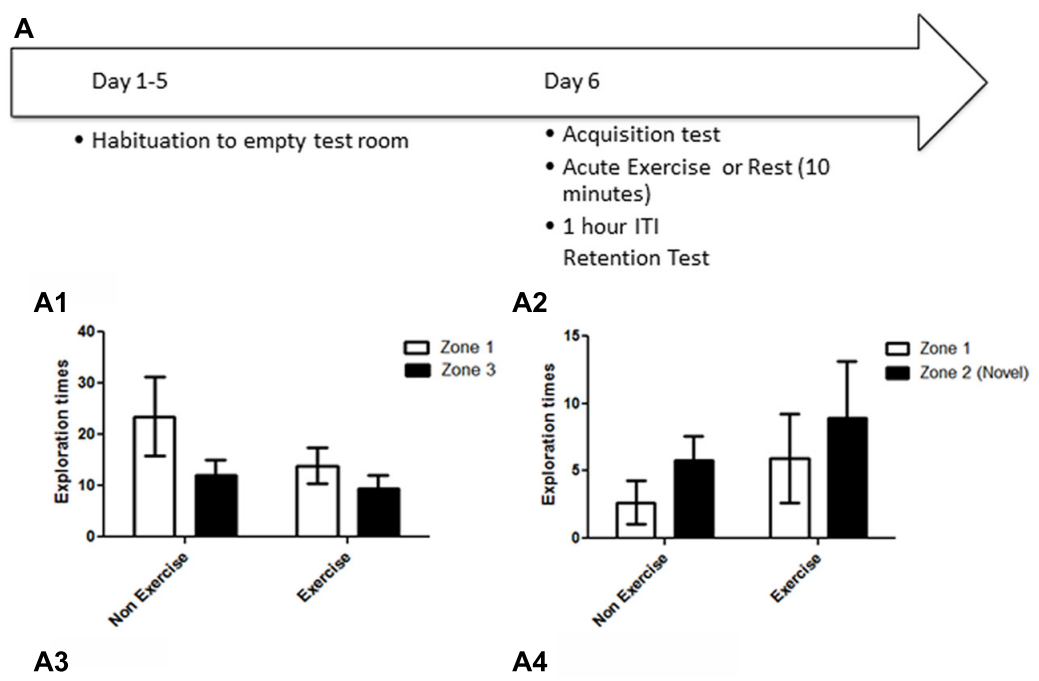

A3

A4
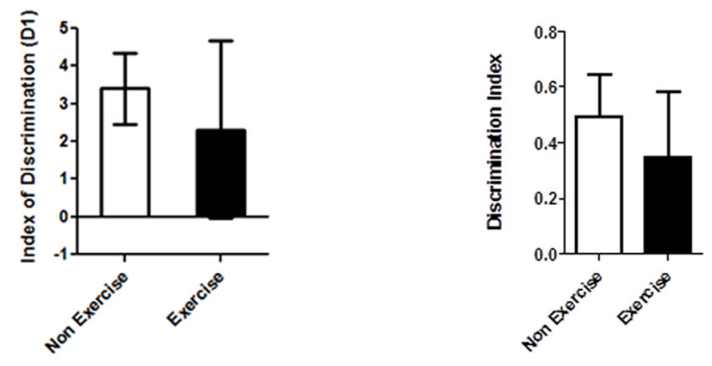

B

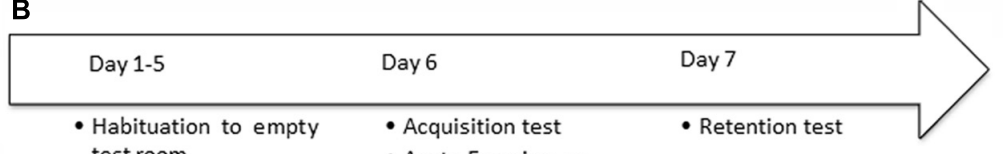

- Habituation to empty test room

BI

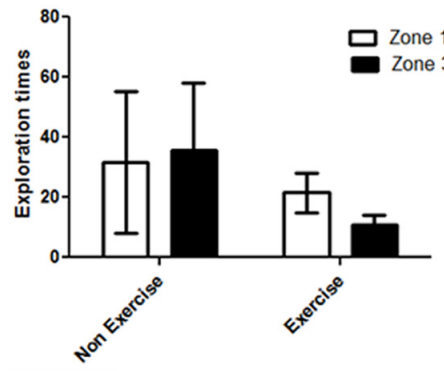

B3

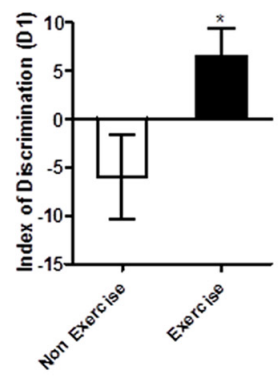

- Acute Exercise or Rest (10 minutes)

B2

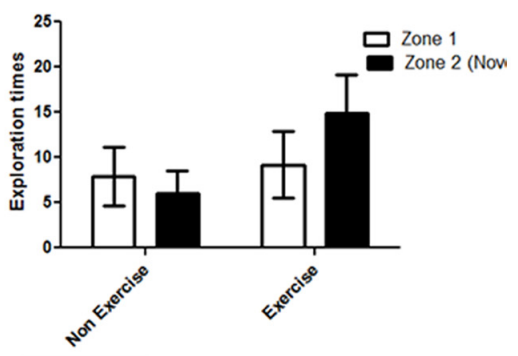

Bu

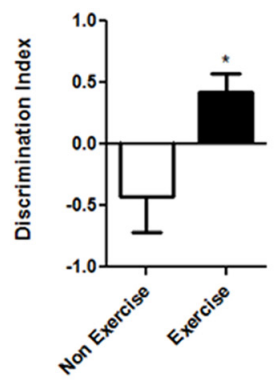

FIGURE 2 | Continued

Frontiers in Aging Neuroscience

www.frontiersin.org

February 2014 | Volume 6 | Article 3 | 6 


\section{FIGURE 2 | Continued}

Schematic showing testing on the OLM task after acute exercise.

Animals were first habituated over 5 days. Following habituation, animals were given a $5 \mathrm{~min}$ of acquisition session to explore the testing room with two identical objects placed in the room. Immediately following the acquisition session, animals in the exercise group were given $10 \mathrm{~min}$ treadmill exercise, while control animals remained sedentary. One hour later, memory was assessed. (B) In a separate experiment, memory was assessed $24 \mathrm{~h}$ after the exercise/rest session: animals underwent an acquisition session ( $5 \mathrm{~min}$ ), followed by exercise/rest (10 $\mathrm{min})$, then $24 \mathrm{~h}$ later a memory test where the location of one of the objects had been changed. (A) Effect of post-trial exercise on performance of aged beagles $1 \mathrm{~h}$ after exercise in the object location memory task. (A1) Object exploration during the acquisition phase of the object location memory task. There was no difference in object exploration of the two objects in the acquisition phase. (A2) One hour after the 10 min exercise regimen neither the exercise group nor the control group could successfully discriminate between the novel and familiar location. (A3) The index of discrimination also did not show any significant difference between the two group, $1 \mathrm{~h}$ after the exercise. (A4) Discrimination index also did not show any significant difference between the two group, $1 \mathrm{~h}$ after the exercise. $n=5-6 / g r o u p$. Error bars show \pm SEM. (B) Effect of post-trial exercise on performance of aged beagles $24 \mathrm{~h}$ after exercise in the object location memory task. (B1) Object exploration during the acquisition phase of the object location memory task. There was no difference in object exploration of the two objects in the acquisition phase. (B2) Twenty-four hour after the 10 min exercise regimen the exercise group showed a trend for greater exploration of the novel location compared to control group, although the effect was not significant. (B3) The index of discrimination showed a significant difference between the two groups $24 \mathrm{~h}$ after exercise. (B4) Discrimination index showed a significant difference between the two groups $24 \mathrm{~h}$ after the exercise. ${ }^{*} p<0.05$. Significant difference between exercise and control group, with only the animals in the exercise group successfully discriminating novel location from familiar. $n=6-8$ /group. Error bars show \pm SEM

\section{NOVEL OBJECT RECOGNITION (NOR) MEMORY}

We used the NOR task as a third assessment of the hypothesis that post-learning exercise can improve consolidation in aged dogs. This test paradigm consisted of a NOR acquisition trial, followed immediately by exercise ( $10 \mathrm{~min}$ ) or rest (controls), and assessment of retention 1 and $24 \mathrm{~h}$ later.

NOR testing revealed that both exercise and control animals were are able to learn the task, but that an acute bout of post-acquisition exercise did not improve consolidation and performance either at short $(1 \mathrm{~h})$ or long-term $(24 \mathrm{~h})$ retention timepoints. Post-acquisition exercise appeared to even slightly impair performance at the $1 \mathrm{~h}$ timepoint. Specifically a repeated measure ANOVA revealed no interaction effect $\left[F_{(1,14)}=0.70\right.$, $p=\mathrm{NS}]$ or main effect of intervention $\left[F_{(1,14)}=0.14, p=\mathrm{NS}\right.$, Figure 3A1 $]$ or object $\left[F_{(1,14)}=0.12, p=N S\right.$, Figure 3A1 $]$ in the acquisition phase of the task. A mixed factor ANOVA with treatment as the between subjects effect and object as the within subjects factor revealed no overall interaction effect $\left[F_{(1,14)}=0.31\right.$, $p=\mathrm{NS}]$, but an effect of object $\left[F_{(1,14)}=11.2, p<0.05\right]$ but not treatment $\left[F_{(1,14)}=0.63, p=\mathrm{NS}\right]$ at the $1 \mathrm{~h}$ timepoint. Post hoc testing revealed an increased exploration of the novel object only in control animals at the $1 \mathrm{~h}$ timepoint $(p<0.05$, Bonferroni post hoc test, Figure 3A2). At the $24 \mathrm{~h}$ timepoint, analysis using a mixed factor ANOVA with treatment as the between subjects effect and object as the within subjects factor revealed no overall interaction effect $\left[F_{(1,13)}=0.00, p=\mathrm{NS}\right]$, but an effect of object $\left[F_{(1,13)}=26.09, p<0.01\right]$ but not treatment $\left[F_{(1,13)}=0.37\right.$,
$p=\mathrm{NS}$ ] and increased exploration of the novel object by both exercise and control animals at the $24 \mathrm{~h}$ timepoint $(p<0.01$, Bonferroni post hoc test, Figure 3B1). There was no difference in the index of discrimination or DI between exercise and control groups at either the $1 \mathrm{~h}$ timepoint ( $p=$ NS; Figures 3A3,A4) or the $24 \mathrm{~h}$ timepoint (Figures 3B2,B3). These results reveal that both exercise and control animals are able to learn this task, and that an acute post-acquisition exercise bout does not improve consolidation or performance in the NOR task, contrasting with the benefits observed for OLM and the concurrent discrimination task.

\section{CHRONIC EXERCISE EFFECTS ON COGNITIVE PERFORMANCE IN AGED DOGS}

In addition to testing how an acute bout of post-learning exercise affects cognitive performance, we investigated the effects of chronic daily exercise on cognitive function using two different chronic exercise approaches as specified beneath.

\section{OBJECT LOCATION MEMORY}

In the first assessment of cognitive benefits of chronic exercise, animals in the exercise group underwent daily treadmill exercise ( $10 \mathrm{~min} /$ day) for 14 consecutive days, followed by a $48 \mathrm{~h}$ break from exercise, prior to cognitive testing. Exercise and control animals then underwent an OLM acquisition trial, and were tested for retention 1 and $24 \mathrm{~h}$ later.

OLM testing revealed significant benefits of chronic daily exercise on memory performance after $24 \mathrm{~h}$ of consolidation, but not at the $1 \mathrm{~h}$ timepoint. Specifically, a repeated measures ANOVA revealed no interaction $\left[F_{(1,12)}=0.01, p=\mathrm{NS}\right]$ or main effect of exercise $\left[F_{(1,12)}=0.26, p=\mathrm{NS}\right]$ or object location $\left[F_{(1,12)}=2.22\right.$, $p=\mathrm{NS}$ ] during the acquisition phase (Figure 4A1). Similarly, there was no interaction effect $\left[F_{(1,13)}=0.6, p=\mathrm{NS}\right]$ or main effect of exercise $\left[F_{(1,13)}=2.14, p=N S\right]$ or object location $\left[F_{(1,13)}=0.13, p=\mathrm{NS}\right]$ at the $1 \mathrm{~h}$ timepoint (Figure 4A2). $t$ Test on the index of discrimination ( $p=$ NS; Figure 4A2) and the DI measure ( $p=$ NS, Figure 4A3) also revealed no effect of exercise.

At the $24 \mathrm{~h}$ timepoint, a repeated measures ANOVA showed a trend for interaction effect $\left[F_{(1,10)}=3.38, p=0.09\right]$. A significant treatment effect was also apparent $24 \mathrm{~h}$ post-acquisition $\left[F_{(1,10)}=12.16, p<0.01\right.$, Figure 4B1], with post hoc analysis revealing that exercised animals, but not controls, showed significantly longer exploration of the object in the novel location than the object in the familiar location $(p<0.05$, Bonferroni post hoc test, Figure 4B1). There was a significant effect of object location $\left[F_{(1,10)}=8.64, p<0.05\right]$. This was also confirmed by analysis of the index of discrimination $(p<0.05$, Figure 4B2) but not by the DI measure ( $p=$ NS, Figure 4B3). These data suggest that chronic exercise boosts memory, particularly when the animal has had sufficient time to encode a memory.

\section{REVERSAL LEARNING TASK}

Finally, we tested if aged dogs benefited from a chronic exercise intervention that occurred with learning. The task consisted of two phases. In the first phase (object discrimination learning), 


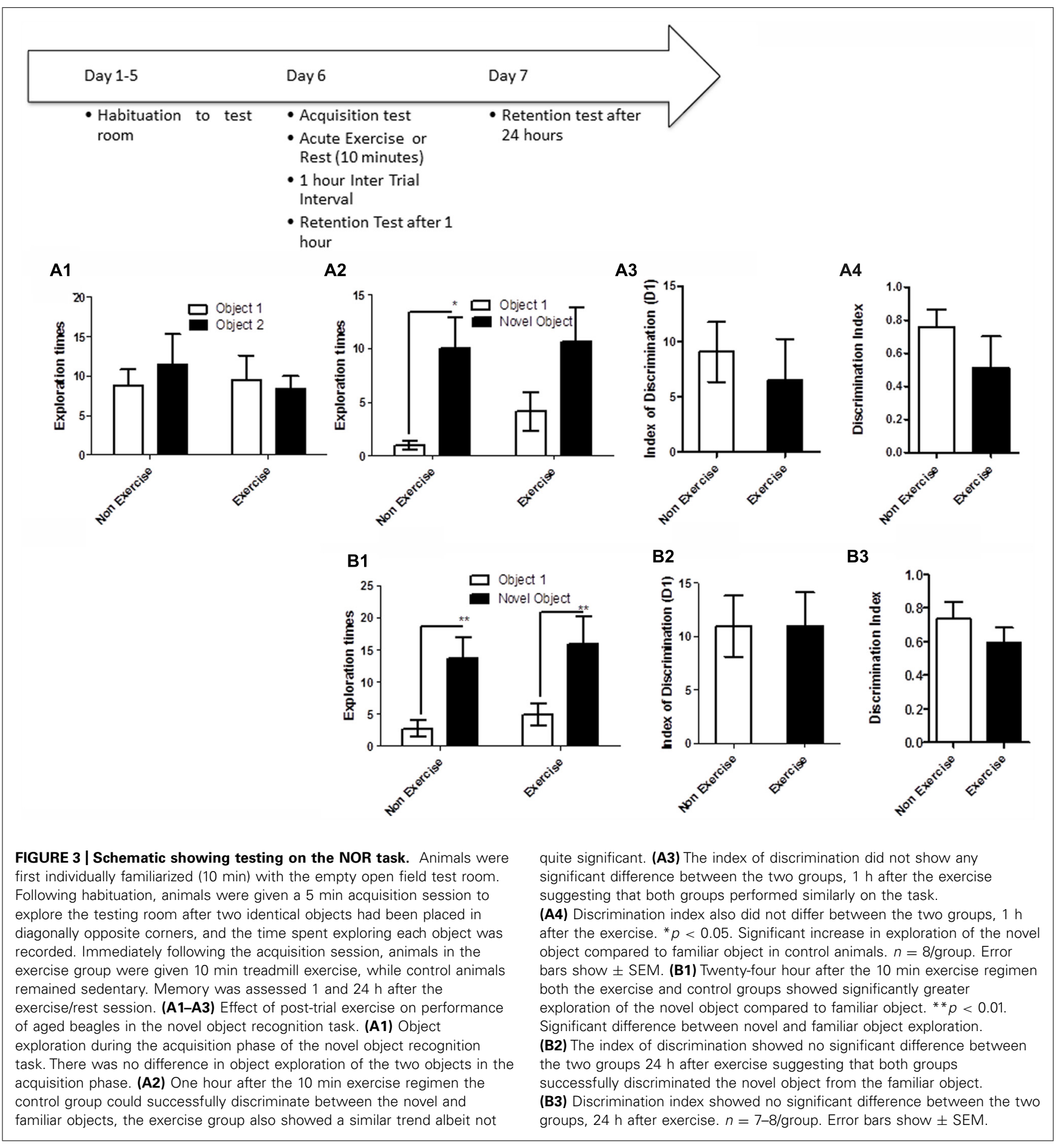

animals were required to discriminate between two objects and reach criterion performance ( $\geq 80 \%$ correct/session). Once animals learned the task to criterion, the reward contingencies were reversed, such that the previously negative stimulus became the positive stimulus and vice versa. This second phase (reversal) assesses cognitive flexibility, and is sensitive to frontal lobe function. For animals in the exercise group, each dog underwent daily exercise (10 min treadmill) immediately prior to the test

session, beginning the day of preference testing and continuing through reversal learning. Days of exercise was determined by the number of days needed to reach criterion, which was on average 2-7 days for the acquisition phase and 7-14 days for the reversal phase.

The results revealed that daily exercise prior to the testing session facilitated reversal learning. Specifically, there was a significant interaction between exercise and trials [repeated measures 


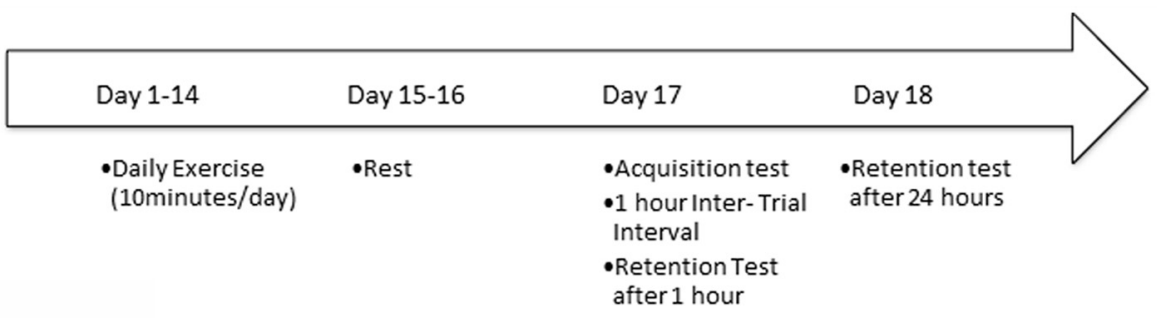

A1

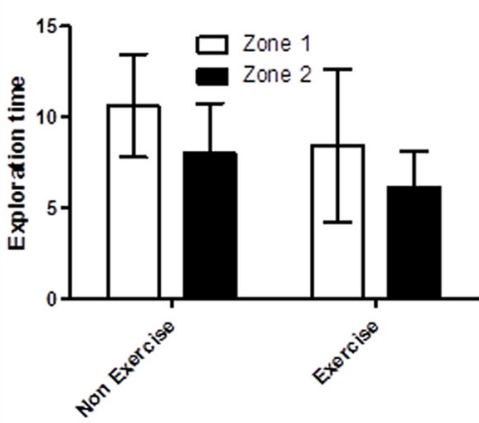

Fig 4.1
A2

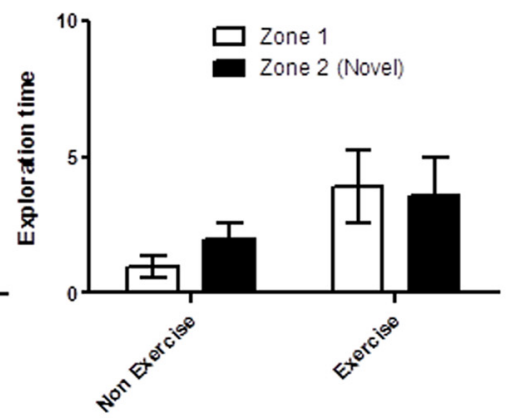

Fig 4.1a
A3

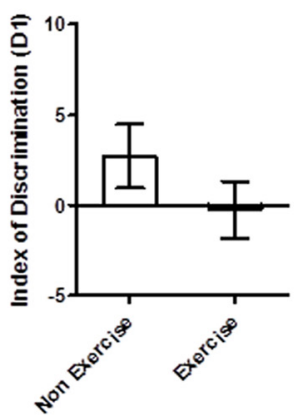

Fig 4.1b

B2

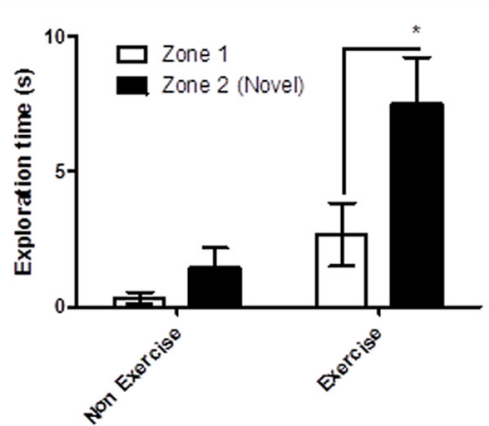

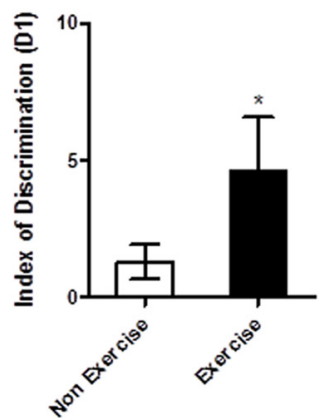

A4

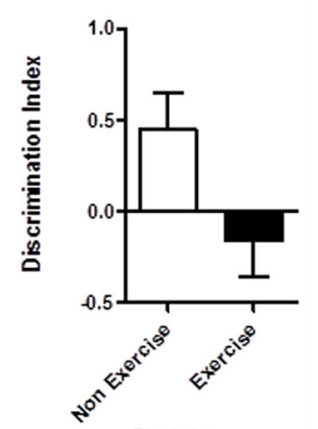

Fig 4.1c

B3

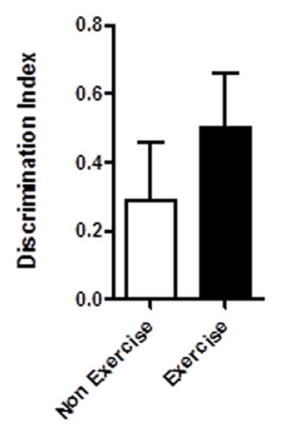

FIGURE 4 | Schematic showing testing on the OLM task after chronic exercise. To test if chronic exercise improved hippocampal function, animals in the exercise group underwent daily treadmill exercise for 14 consecutive days. Two days later, all animals were given a 5 min acquisition session to explore two identical objects that had been placed in diagonally opposite corners of the testing room, and the time spent exploring each object was recorded. Retention memory was tested at 1 and $24 \mathrm{~h}$ after the acquisition trial. (A2-B2) Effect of 14 days of exercise on performance of aged beagles in the object location memory task conducted $48 \mathrm{~h}$ after last exercise session. (A1) Object exploration during the acquisition phase of the object location memory task. There was no difference in object exploration of the two objects in the acquisition phase. (A2) One hour after the acquisition animals were tested on the object location memory task and neither the exercise group nor the control group could successfully discriminate between the novel and familiar location. (A3) The index of discrimination also did not show any significant difference between the two group, $1 \mathrm{~h}$ after the exercise. (A4) Discrimination index also did not show any significant difference between the two groups, $1 \mathrm{~h}$ after exercise. $n=6-8 /$ group. Error bars show \pm SEM. (B1) Twenty-four hours after the acquisition phase or $48 \mathrm{~h}$ after the last exercise session, the exercise group showed greater exploration of the novel location compared to control group. (B2) The index of discrimination showed a significant difference between the two groups $24 \mathrm{~h}$ after acquisition. (B3) Discrimination index did not show any significant difference between the two groups, $24 \mathrm{~h}$ after acquisition. $p<0.05$. ${ }^{*}$ Significant difference between exercise and control group, with only the animals in the exercise group successfully discriminating between the novel and familiar locations. Error bars show \pm SEM. $n=6 /$ group.
ANOVA: $F_{(1,16)}=4.93, p<0.05$ ], with the exercise group making significantly fewer errors than controls in reversal learning (Bonferroni corrected $t$-test, $p<0.05$, Figure 5A1). Overall, animals in both groups made significantly more errors in the reversal learning than in the initial acquisition learning $\left[F_{(1,16)}=41.47\right.$, $p<0.001$ ], demonstrating that reversal learning is more difficult than the initial task acquisition phase. These results suggest that daily exercise concurrent with learning improves cognitive flexibility in aged dogs, allowing the animals to more rapidly learn that "the rules have changed."

\section{DISCUSSION}

This study was designed to evaluate the effects of exercise on cognitive function and memory consolidation. The results demonstrate that cognitive function can be improved by both short durations of increased physical activity as well as a program of daily exercise for 2 weeks. We found that exercise improved performance of aged beagles in several different behavioral tasks in a time-dependent manner. The improvements were robust at $24 \mathrm{~h}$ post-exercise; by contrast much smaller or insignificant effects were observed when animals were tested either immediately or $1 \mathrm{~h}$ after exercise 


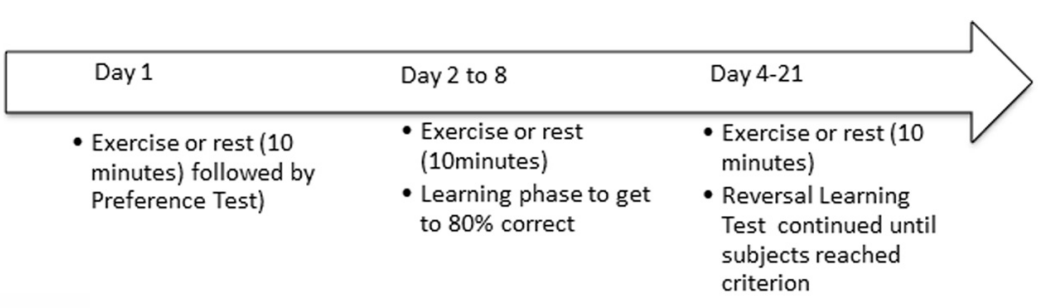

A1

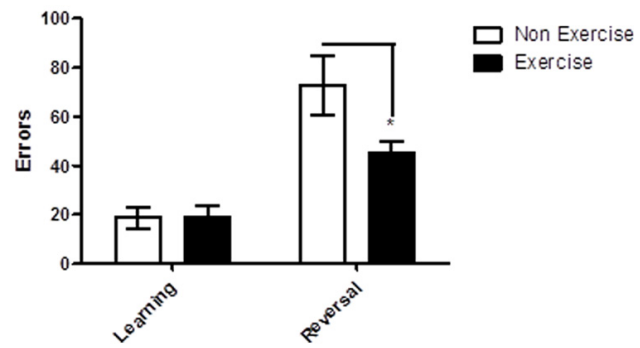

FIGURE 5 | Schematic showing testing of animals on the reversal learning task. After identifying each animal's preferred/non-preferred objects for a given object pair on day 1, animals learned to associate a positive food reward with the preferred object over the next week. Once the criterion of $\geq 80 \%$ correct responses was reached in a day's session, reversal learning was initiated. Animals were tested on the reversal phase until the animal achieved reached criterion $(\geq 80 \%$ correct in a single session). For animals in the exercise group, each dog underwent daily exercise (10 min treadmill) immediately prior to the test session, beginning the day of preference testing and continuing through reversal learning.
Subjects in the control group remained sedentary in a metabolic or veri-kennel for $10 \mathrm{~min}$. (A1) Effect of pre-trial exercise on performance of aged beagles in the reversal learning task. Performance on learning or discrimination phase of the task did not differ between control animals and those in the exercise group. There was a significant effect of task, in that, both groups made more errors in acquiring the reversal task compared to initial discrimination task. There was also a significant difference between the exercise and control group in the number of errors to reach criterion in the reversal phase of the task. ${ }^{*} p<0.05$. Error bars show \pm SEM. $n=11 /$ group. (for summary see Table 1). Animals in the exercise group showed improved consolidation in the concurrent discrimination task and a spatial task. We also found improvements in a chronic exercise design in the object location and reversal learning tasks. It is important to note that we used aged canines (mean age of 10.6 year at the start of the study). This is potentially significant since human studies aiming to demonstrate the effect of exercise to improve memory in aging have resulted in variable outcomes (Madden et al., 1989; Colcombe and Kramer, 2003; Roig et al., 2013). Studies in rodents have shown that aged animals can learn and acquire novel information but impairment in retention is observed as the delay is increased (Driscoll et al., 2006; Bizon et al., 2009).

The concurrent discrimination tasks measures the ability to remember object-object association in the presence of active interference in the form of a list of objects (Buffalo et al., 1998; Broadbent etal., 2007). Aged primates have been reported to show deficits in performance on the concurrent discrimination task (Moss et al., 1981). However, this is the first study to use this task in canine subjects to show that acute exercise can help improve performance in this task. This task is different from the traditional two choice simple discrimination task, in that, the animals cannot solve the task based on the degree of familiarity with particular stimuli (recognition memory) because of the presence of interference (Gaffan and Murray, 1992). Our results also support this difference, in that while the aged control animals performed poorly in the concurrent discrimination task (preexercise versus post-exercise comparisons), they did not appear impaired in a NOR task. Although it has been suggested that the concurrent discrimination task in monkeys is based on familiarity, in humans it is shown to be MTL-dependent learning (Hood et al., 1999). It is important to note that while there was no difference in performance between the control and exercise groups immediately after the exercise, there was a significant improvement in performance $24 \mathrm{~h}$ the exercise session. This suggests that the effects observed in this study are because of longer term downstream effects of exercise rather than improved short-term memory.

Based on the results from the concurrent discrimination task where we observed post-exercise effects, we hypothesized that exercise improved memory consolidation rather than learning. To test this hypothesis animals were tested on an OLM task in a post-trial exercise paradigm. The OLM task is a measure of spatial discrimination and is considered to involve a hippocampus-dependent mechanism (Intlekofer et al., 2013). Similar to the concurrent discrimination task, we found that the effects of acute exercise on promoting memory function were only observed $24 \mathrm{~h}$ posttraining in the OLM task. When animals were tested $1 \mathrm{~h}$ after the exercise sessions, they did not show any improved recollection of the spatial location of objects. This further supports the hypothesis that the effects of exercise that we observe in this study are not a result of arousal but longer term downstream affects that are either recruited, or persist for as long as $24 \mathrm{~h}$ after a single bout of exercise. It is also important to note that in this study exercise training occurred after the acquisition trial. We have recently 
Table 1 |The effect of exercise on different behavioral measures.

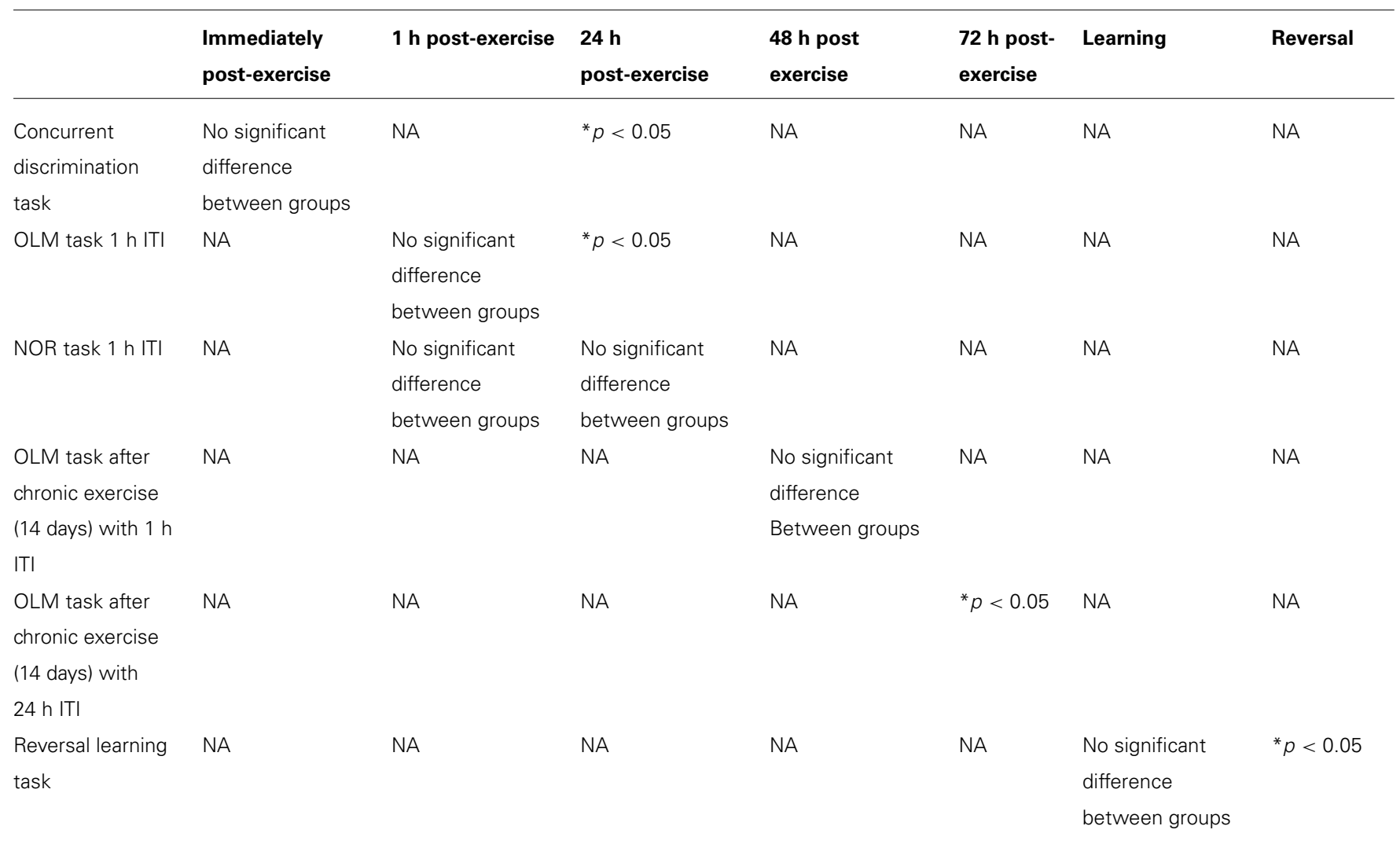

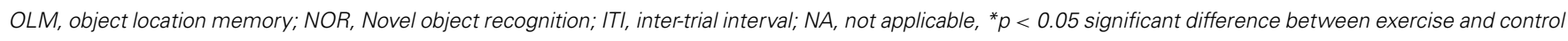
groups.

demonstrated that post-trial exercise intervention facilitates memory consolidation in amnestic mild cognitive impairment (aMCI) patients (Segal et al., 2012). It should be noted however, that the Segal study, involved recall of emotional images. The task used by Segal and colleagues is thus different from concurrent discrimination task and OLM tasks. Moreover, testing was done at $1 \mathrm{~h}$ post-exercise which is distinct from the current data which shows improved performance $24 \mathrm{~h}$ post-treatment. However, it is evident that both human and canine data support the role of exercise as a mechanism to improve memory consolidation. Our findings confirm and extend human studies on post-trial learning mechanisms and attest to the value of canine as a model of aging.

The aged beagles were also tested in a NOR task designed to evaluate the effects of exercise on a task that utilized minimal spatial learning and hippocampal involvement. Interestingly there was no significant difference in the discrimination ability of animals in exercise and control groups in this task. Performance in the NOR task is thought to rely primarily on the perirhinal cortex (Aggleton et al., 1997; Ennaceur and Aggleton, 1997; Aggleton and Brown, 2005). In this study we found that aged beagles in the control groups were able to distinguish novel from familiar, this effect persisted in the exercise group also. Thus it may be possible that the perirhinal cortex is relatively spared in aging. These data are similar to those in aged rodents where long-term exercise improves recall for OLM but not object recognition memory (Siette et al.,
2013). However, it is important to note that there may be alternate explanations which could explain the lack of effect of exercise in the NOR task. It is possible that there was no difference between the two groups because of ceiling effects in the control animals rather than a lack of efficacy on perirhinal-dependent function. Further studies will be needed to determine the more plausible explanation.

A novel finding that emerges from this study is the idea that acute exercise impacts the MTL memory systems in a timedependent manner. It is important to compare the effects of acute exercise vs. chronic exercise on improving cognitive function in the canine model using similar tasks. Therefore in a chronic exercise study, dogs were allowed to run on the treadmill for 14 days (10 $\mathrm{min} /$ day) and were then given a break of $48 \mathrm{~h}$ before being tested on the object location task. Our results indicated that exercise had a lasting a benefit that resulted in improved OLM even $48-72 \mathrm{~h}$ after the last exercise session. This is consistent with several other studies which have shown lasting improvements in cognitive function following increased physical activity. It is important to note that no effect of exercise was observed $1 \mathrm{~h}$ post-acquisition even after a chronic exercise regime. This agrees with data from acute exercise treatment and suggests that exercise-induced improvement in learning and memory involves consolidation and retrieval rather than memory acquisition. In a recent article Roig et al., suggested an interesting dissociation 
between the effects of acute and chronic exercise on human memory (Segal et al., 2012; Roig et al., 2013). The authors suggested that while acute exercise impact memory consolidation in a time-dependent manner, chronic exercise is more likely to induce physiological adaptations which prime the molecular machinery of the brain to augment memory processing. This is consistent with our findings that $24 \mathrm{~h}$ retention of OLM was improved even when testing was conducted $48-72 \mathrm{~h}$ after the last exercise session. Overall, our findings show that acute and chronic exercise treatment regimes share the ability to facilitate memory consolidation and are effective in improving cognitive function.

Finally the animals were tested on a reversal learning test, which is used to measures executive function. The NIH toolbox cognitive function battery defines executive function as control of goal directed behavior (Snigdha et al., 2013; Weintraub et al., 2013). It includes concept formation and manipulation of information in response to environmental cues and requires active involvement of the frontal lobe. Typically the reversal learning task which requires learning and then unlearning a rule based on change in reinforcement contingencies is a useful measure of executive function (Tapp et al., 2003,2004). In this study we found that exercise did not affect performance on the learning phase but significantly improved the errors to criterion in the reversal phase of the reversal learning task. This suggests a selective improvement in the reversal but not learning phase of the task, with the animals in the control group making more perseverative responses. Our data suggest that exercise may not impact simple cognitive functions as required in the first (learning) phase of the task. However, discrimination reversals which require subjects to show inhibitory control and discontinue prepotent responses to a previously correct stimulus, is improved by exercise.

We would like to point out that while aged beagles provide a unique advantage as a model for studies of aging, there are some limitations of using this model. For instance, due to limited availability of aging dogs all tests reported here were conducted in the same animals and the low number of animals for single trial tests may reduce power to detect some effects. Furthermore, like humans, aged dogs demonstrate domain-specific deficits in learning and memory as well as individual variability (Adams et al., 2000; Tapp etal., 2003). It is important to note that individual variability can have a confounding effect in studies (as seen in this study). We have, however, tried to control for some of these effects in this study by distributing animals from all three dietary groups equally between control and exercise groups as stated previously. We would also like to note that although the handling of the exercise group and not controls during the exercise training may lead to some confounds, it would stand to reason that any effects of handling would be expected to have the greatest effects early in testing, where no treatment effects were observed.

Finally, although age-related effects were not established in this paper, we have in the past demonstrated age-related differences in performance in many of the tasks used here (Tapp et al., 2003; Cotman and Head, 2008). Thus, despite potential confounds, our data clearly suggest that the mechanisms to improve overall memory and cognitive function remain accessible in aged animals and can be re-engaged with physical exercise.
In summary, the results of this study indicate that acute and chronic exercise are both effective against the functional deficits associated with cognitive aging. Exercise may therefore be a viable training mechanism to improve cognitive reserve in the brain and bolster resiliency against the consequences of brain aging.

\section{ACKNOWLEDGMENT}

This work was funded by a grant (AG012694-16) from the National Institute of Aging. We would also like to thank Dr. Nicole Berchtold for her expert comments and edits on the manuscript.

\section{REFERENCES}

Adams, B., Chan, A., Callahan, H., and Milgram, N. W. (2000). The canine as a model of human cognitive aging: recent developments. Prog. Neuropsychopharmacol. Biol. Psychiatry 24, 675-692. doi: 10.1016/S0278-5846(00) 00101-9

Aggleton, J. P., and Brown, M. W. (2005). Contrasting hippocampal and perirhinal cortex function using immediate early gene imaging. Q. J. Exp. Psychol. B Comp. Physiol. Psychol. 58, 218-233.

Aggleton, J. P., Keen, S., Warburton, E. C., and Bussey, T. J. (1997). Extensive cytotoxic lesions involving both the rhinal cortices and area TE impair recognition but spare spatial alternation in the rat. Brain Res. Bull. 43, 279-287. doi: 10.1016/S0361-9230(97)00007-5

Bach, M. E., Barad, M., Son, H., Zhuo, M., Lu, Y. F., Shih, R., et al. (1999). Agerelated defects in spatial memory are correlated with defects in the late phase of hippocampal long-term potentiation in vitro and are attenuated by drugs that enhance the cAMP signaling pathway. Proc. Natl. Acad. Sci. U.S.A. 96, 5280-5285. doi: $10.1073 /$ pnas. 96.9 .5280

Barnes, D. E., and Yaffe, K. (2011). The projected effect of risk factor reduction on Alzheimer's disease prevalence. Lancet Neurol. 10, 819-828. doi: 10.1016/S14744422(11)70072-2

Bekinschtein, P., Cammarota, M., Igaz, L. M., Bevilaqua, L. R., Izquierdo, I., and Medina, J. H. (2007). Persistence of long-term memory storage requires a late protein synthesis- and BDNF-dependent phase in the hippocampus. Neuron 53 , 261-277. doi: 10.1016/j.neuron.2006.11.025

Berchtold, N. C., Kesslak, J. P., and Cotman, C. W. (2002). Hippocampal brainderived neurotrophic factor gene regulation by exercise and the medial septum. J. Neurosci. Res. 68, 511-521. doi: 10.1002/jnr.10256

Bizon, J. L., LaSarge, C. L., Montgomery, K. S., McDermott, A. N., Setlow, B., and Griffith, W. H. (2009). Spatial reference and working memory across the lifespan of male Fischer 344 rats. Neurobiol. Aging 30, 646-655. doi: 10.1016/j.neurobiolaging.2007.08.004

Broadbent, N. J., Squire, L. R., and Clark, R. E. (2007). Rats depend on habit memory for discrimination learning and retention. Learn. Mem. 14, 145-151. doi: $10.1101 / \mathrm{lm} .455607$

Buckner, R. L. (2003). Functional-anatomic correlates of control processes in memory. J. Neurosci. 23, 3999-4004.

Buffalo, E. A., Stefanacci, L., Squire, L. R., and Zola, S. M. (1998). A reexamination of the concurrent discrimination learning task: the importance of anterior inferotemporal cortex, area TE. Behav. Neurosci. 112, 3-14. doi: 10.1037/0735-7044.112.1.3

Burke, S. N., Hartzell, A. L., Lister, J. P., Hoang, L. T., and Barnes, C. A. (2012). Layer $V$ perirhinal cortical ensemble activity during object exploration: a comparison between young and aged rats. Hippocampus 22, 2080-2093. doi: 10.1002/hipo.22066

Burke, S. N., Wallace, J. L., Hartzell, A. L., Nematollahi, S., Plange, K., and Barnes, C. A. (2011). Age-associated deficits in pattern separation functions of the perirhinal cortex: a cross-species consensus. Behav. Neurosci. 125, 836-847. doi: $10.1037 / \mathrm{a} 0026238$

Cahill, L., and Alkire, M. T. (2003). Epinephrine enhancement of human memory consolidation: interaction with arousal at encoding. Neurobiol. Learn. Mem. 79, 194-198. doi: 10.1016/S1074-7427(02)00036-9

Colcombe, S., and Kramer, A. F. (2003). Fitness effects on the cognitive function of older adults: a meta-analytic study. Psychol. Sci. 14, 125-130. doi: 10.1111/14679280.t01-1-01430 
Cotman, C. W., and Berchtold, N. C. (2007). Physical activity and the maintenance of cognition: learning from animal models. Alzheimers Demen. 3, S30-S37. doi: 10.1016/j.jalz.2007.01.013

Cotman, C. W., Berchtold, N. C., and Christie, L. A. (2007). Exercise builds brain health: key roles of growth factor cascades and inflammation. Trends Neurosci. 30, 464-472. doi: 10.1016/j.tins.2007.06.011

Cotman, C. W., and Head, E. (2008). The canine (dog) model of human aging and disease: dietary, environmental and immunotherapy approaches. J. Alzheimers Dis. 15, 685-707.

Dao, A. T., Zagaar, M. A., Levine, A. T., Salim, S., Eriksen, J. L., and Alkadhi, K. A. (2013). Treadmill exercise prevents learning and memory impairment in Alzheimer's disease-like pathology. Curr. Alzheimer Res. 10, 507-515. doi: $10.2174 / 1567205011310050006$

Davis, H. P., and Squire, L. R. (1984). Protein synthesis and memory: a review. Psychol. Bull. 96, 518-559. doi: 10.1037/0033-2909.96.3.518

Driscoll, I., Howard, S. R., Stone, J. C., Monfils, M. H., Tomanek, B., Brooks W. M., et al. (2006). The aging hippocampus: a multi-level analysis in the rat Neuroscience 139, 1173-1185. doi: 10.1016/j.neuroscience.2006.01.040

Ennaceur, A., and Aggleton, J. P. (1997). The effects of neurotoxic lesions of the perirhinal cortex combined to fornix transection on object recognition memory in the rat. Behav. Brain Res. 88, 181-193. doi: 10.1016/S0166-4328(97)02297-3

Fahnestock, M., Marchese, M., Head, E., Pop, V., Michalski, B., Milgram, W. N., et al. (2012). BDNF increases with behavioral enrichment and an antioxidant diet in the aged dog. Neurobiol. Aging 33, 546-554. doi: 10.1016/j.neurobiolaging.2010.03.019

Gaffan, D., and Murray, E. A. (1992). Monkeys (Macaca fascicularis) with rhinal cortex ablations succeed in object discrimination learning despite 24-hr intertria intervals and fail at matching to sample despite double sample presentations. Behav. Neurosci. 106, 30-38. doi: 10.1037/0735-7044.106.1.30

Hasher, L., and Zachs, R. T. (1988). Working memory, comprehension, and aging: a review and new view. Psychol. Learn. Motiv. 22, 193-225. doi: 10.1016/S00797421(08)60041-9

Head, E., Pop, V., Vasilevko, V., Hill, M., Saing, T., Sarsoza, F., et al. (2008). A twoyear study with fibrillar beta-amyloid (A beta) immunization in aged canines: effects on cognitive function and brain A beta. J. Neurosci. 28, 3555-3566. doi 10.1523/JNEUROSCI.0208-08.2008

Holdstock, J. S., Mayes, A. R., Roberts, N., Cezayirli, E., Isaac, C. L., O’Reilly, R. C., et al. (2002). Under what conditions is recognition spared relative to recall after selective hippocampal damage in humans? Hippocampus 12, 341-351. doi: 10.1002/hipo.10011

Hood, K. L., Postle, B. R., and Corkin, S. (1999). An evaluation of the concurrent discrimination task as a measure of habit learning: performance of amnesic subjects. Neuropsychologia 37, 1375-1386. doi: 10.1016/S0028-3932(99)00048-2

Intlekofer, K. A., Berchtold, N. C., Malvaez, M., Carlos, A. J., McQuown, S. C., Cunningham, M. J., et al. (2013). Exercise and sodium butyrate transform a subthreshold learning event into long-term memory via a brainderived neurotrophic factor-dependent mechanism. Neuropsychopharmacology doi:10.1038/npp.2013.104

Kannangara, T. S., Lucero, M. J., Gil-Mohapel, J., Drapala, R. J., Simpson, J. M., Christie, B. R., etal. (2011). Running reduces stress and enhances cell genesis in aged mice. Neurobiol. Aging 32, 2279-2286. doi: 10.1016/j.neurobiolaging.2009.12.025

Kronenberg, G., Bick-Sander, A., Bunk, E., Wolf, C., Ehninger, D., and Kempermann, G. (2006). Physical exercise prevents age-related decline in precursor cell activity in the mouse dentate gyrus. Neurobiol. Aging 27, 1505-1513. doi: 10.1016/j.neurobiolaging.2005.09.016

Lai, Z. C., Moss, M. B., Killiany, R. J., Rosene, D. L., and Herndon, J. G. (1995) Executive system dysfunction in the aged monkey: spatial and object reversallearning. Neurobiol. Aging 16, 947-954. doi: 10.1016/0197-4580(95)02014-4

Lister, J. P., and Barnes, C. A. (2009). Neurobiological changes in the hippocampus during normative aging. Arch. Neurol. 66, 829-833. doi: 10.1001/archneurol.2009.125

Liu, H. L., Zhao, G., Cai, K., Zhao, H. H., and Shi, L. D. (2011). Treadmill exercise prevents decline in spatial learning and memory in APP/PS1 transgenic mice through improvement of hippocampal long-term potentiation. Behav. Brain Res. 218, 308-314. doi: 10.1016/j.bbr.2010.12.030

Madden, D. J., Blumenthal, J. A., Allen, P. A., and Emery, C. F. (1989). Improving aerobic capacity in healthy older adults does not necessarily lead to improved cognitive performance. Psychol. Aging 4, 307-320. doi: 10.1037/0882-7974.4. 3.307

McAlonan, K., and Brown, V. J. (2003). Orbital prefrontal cortex mediates reversal learning and not attentional set shifting in the rat. Behav. Brain Res. 146, 97-103. doi: 10.1016/j.bbr.2003.09.019

McGaugh, J. L. (1966). Time-dependent processes in memory storage. Science 153, 1351-1358. doi: 10.1126/science.153.3742.1351

McGaugh, J. L. (2000). Memory: a century of consolidation. Science 287, 248-251. doi: $10.1126 /$ science. 287.5451 .248

McKenzie, S., and Eichenbaum, H. (2011). Consolidation and reconsolidation: two lives of memories? Neuron 71, 224-233. doi: 10.1016/j.neuron.2011.06.037

Milgram, N. W., Head, E., Weiner, E., and Thomas, E. (1994). Cognitive functions and aging in the dog: acquisition of nonspatial visual tasks. Behav. Neurosci. 108, 57-68. doi: 10.1037/0735-7044.108.1.57

Milgram, N. W., Head, E., Zicker, S. C., Ikeda-Douglas, C., Murphey, H., Muggenberg, B. A., et al. (2004). Long-term treatment with antioxidants and a program of behavioral enrichment reduces age-dependent impairment in discrimination and reversal learning in beagle dogs. Exp. Gerontol. 39, 753-765. doi: 10.1016/j.exger.2004.01.007

Moss, M., Mahut, H., and Zola-Morgan, S. (1981). Concurrent discrimination learning of monkeys after hippocampal, entorhinal, or fornix lesions. J. Neurosci. 1, 227-240.

Mumby, D. G., Gaskin, S., Glenn, M. J., Schramek, T. E., and Lehmann, H. (2002a). Hippocampal damage and exploratory preferences in rats: memory for objects, places, and contexts. Learn. Mem. 9, 49-57. doi: 10.1101/lm.41302

Mumby, D. G., Glenn, M. J., Nesbitt, C., and Kyriazis, D. A. (2002b). Dissociation in retrograde memory for object discriminations and object recognition in rats with perirhinal cortex damage. Behav. Brain Res. 132, 215-226. doi: 10.1016/S01664328(01)00444-2

Park, H., and Poo, M. M. (2013). Neurotrophin regulation of neural circuit development and function. Nat. Rev. Neurosci. 14, 7-23. doi: 10.1038/nrn3379

Radak, Z., Kaneko, T., Tahara, S., Nakamoto, H., Pucsok, J., Sasvari, M., Nyakas, C., and Goto, S. (2001). Regular exercise improves cognitive function and decreases oxidative damage in rat brain. Neurochem. Int. 38, 17-23. doi: 10.1016/S01970186(00)00063-2

Roig, M., Nordbrandt, S., Geertsen, S. S., and Nielsen, J. B. (2013). The effects of cardiovascular exercise on human memory: a review with meta-analysis. Neurosci. Biobehav. Rev. 37, 1645-1666. doi: 10.1016/j.neubiorev.2013.06.012

Scoville, W. B., and Milner, B. (1957). Loss of recent memory after bilateral hippocampal lesions. J. Neurol. Neurosurg. Psychol. 20, 11-21. doi: 10.1136/jnnp.20.1.11

Segal, S. K., Cotman, C. W., and Cahill, L. F. (2012). Exercise-induced noradrenergic activation enhances memory consolidation in both normal aging and patients with amnestic mild cognitive impairment. J. Alzheimers Dis. 32, 1011-1018. doi: 10.3233/JAD-2012-121078

Siette, J., Westbrook, R. F., Cotman, C., Sidhu, K., Zhu, W., Sachdev, P., et al. (2013). Age-specific effects of voluntary exercise on memory and the older brain. Biol. Psychiatry 73, 435-442. doi: 10.1016/j.biopsych.2012.05.034

Snigdha, S., Berchtold, N., Astarita, G., Saing, T., Piomelli, D., and Cotman, C. W. (2011). Dietary and behavioral interventions protect against age related activation of caspase cascades in the canine brain. PLoS ONE 6:e24652. doi:10.1371/journal.pone.0024652

Snigdha, S., Milgram, N. W., Willis, S. L., Albert, M., Weintraub, S., Fortin, N. J., et al. (2013). A preclinical cognitive test battery to parallel the National Institute of Health Toolbox in humans: bridging the translational gap. Neurobiol. Aging 34, 1891-1901. doi: 10.1016/j.neurobiolaging.2013.01.018

Squire, L. R. (2004). Memory systems of the brain: a brief history and current perspective. Neurobiol. Learn. Mem. 82, 171-177. doi: 10.1016/j.nlm.2004.06.005 Squire, L. R., Stark, C. E. L., and Clark, R. E. (2004). The medial temporal lobe. Annu. Rev. Neurosci. 27, 279-306. doi: 10.1146/annurev.neuro.27.070203.144130 Squire, L. R., Zola-Morgan, S., and Chen, K. S. (1988). Human amnesia and animal models of amnesia: performance of amnesic patients on tests designed for the monkey. Behav. Neurosci. 102, 210-221. doi: 10.1037/0735-7044.102.2.210

Stalnaker, T. A., Franz, T. M., Singh, T., and Schoenbaum, G. (2007). Basolateral 35 amygdala lesions abolish orbitofrontal-dependent reversal impairments. Neuron 54, 51-58. doi: 10.1016/j.neuron.2007.02.014

Tapp, P. D., Siwak, C. T., Estrada, J., Head, E., Muggenburg, B. A., Cotman, C. W., et al. (2003). Size and reversal learning in the beagle dog as a measure of 
executive function and inhibitory control in aging. Learn. Mem. 10, 64-73. doi: 10.1101/lm.54403

Tapp, P. D., Siwak, C. T., Gao, F. Q., Chiou, J. Y., Black, S. E., Head, E., et al. (2004). Frontal lobe volume, function, and beta-amyloid pathology in a canine model of aging. J. Neurosci. 24, 8205-8213. doi: 10.1523/JNEUROSCI.1339-04.2004

van Praag, H., Christie, B. R., Sejnowski, T. J., and Gage, F. H. (1999). Running enhances neurogenesis, learning, and long-term potentiation in mice. Proc. Natl. Acad. Sci. U.S.A. 96, 13427-13431. doi: 10.1073/pnas.96.23.13427

van Praag, H., Shubert, T., Zhao, C., and Gage, F. H. (2005). Exercise enhances learning and hippocampal neurogenesis in aged mice. J. Neurosci. 25, 8680-8685. doi: 10.1523/JNEUROSCI.1731-05.2005

Weintraub, S., Dikmen, S. S., Heaton, R. K., Tulsky, D. S., Zelazo, P. D., Bauer, P. J., et al. (2013). Cognition assessment using the NIH Toolbox. Neurology 80, S54-S64. doi: 10.1212/WNL.0b013e3182872ded

Winters, B. D., and Bussey, T. J. (2005). Transient inactivation of perirhinal cortex disrupts encoding, retrieval, and consolidation of object recognition memory. $J$. Neurosci. 25, 52-61. doi: 10.1523/JNEUROSCI.3827-04.2005
Conflict of Interest Statement: The authors declare that the research was conducted in the absence of any commercial or financial relationships that could be construed as a potential conflict of interest.

Received: 09 September 2013; accepted: 08 January 2014; published online: 03 February 2014.

Citation: Snigdha S, de Rivera C, Milgram NW and Cotman CW (2014) Exercise enhances memory consolidation in the aging brain. Front. Aging Neurosci. 6:3. doi: 10.3389/fnagi.2014.00003

This article was submitted to the journal Frontiers in Aging Neuroscience.

Copyright (C) 2014 Snigdha, de Rivera, Milgram and Cotman. This is an open-access article distributed under the terms of the Creative Commons Attribution License (CC BY). The use, distribution or reproduction in other forums is permitted, provided the original author(s) or licensor are credited and that the original publication in this journal is cited, in accordance with accepted academic practice. No use, distribution or reproduction is permitted which does not comply with these terms. 